Space for Remembrance. Chacabuco: Saltpeter Office and Prison Camp
| RESUMEN |

Basado en el documental NostalciA de LA Luz de Patricio Guzmán, el proyecto se concibe como una crítica al proceso de construcción social de la memoria a partir de la concepción benjaminiana del concepto "Historia". Una propuesta arquitectónica que interviene la Oficina Salitrera y Campo de Prisioneros Chacabuco, entendiendo la conmemoracion como una experiencia espacial.

\section{| ABSTRACT |}

Based on the documentary Nostalgia de la Luz (20I0) by Patricio Guzman, this project is conceived as a critique of the process of social construction of memory from Benjamin's conception of "History". An architectural proposal involving the Saltpeter Office and Chacabuco Prison Camp, understanding the commemoration as a spatial experience.

\title{
Espacio para la rememoración. Oficina Salitrera y Campo de Prisioneros Chacabuco
}

"La verdad es el espectro que asedia a la historia como su primera y última determinación; su principio y fin, su origen y su destino. Que la verdad aparezca a la vez como el principio y el fin de la historia, como su origen y su destino, no significa que la historia sea, sin más, la verdad; significa más bien que la verdad es la cifra con la que ella se mide. La verdad es la medida de la historia, lo que discierne su especificidad, lo que, en y por principio, la destina a diferenciarse, por ejemplo, del mito, la fábula, del cuento o de la ficción".

Collingwood-Selby, 2009, p. 11

\section{CONTEXTO GENERAL}

El constante frenesí de los procesos económicos y avances tecnológicos de la vida actual, nos hace creer que las condiciones para recordar son innecesarias, las cuales, comprometidas con una sociedad olvidada del pasado y cegada por el presente, han sido relegadas por la satisfacción instantánea y las ansias del futuro. En este sentido, cabe preguntarse: ¿̇Para qué recordar? ¿Qué recordar?

Actualmente, situados en un contexto social tan desfavorable para la memoria, se busca romper con la tendencia al olvido existente a partir de una mirada frente a dos hechos históricos particulares en la historia de Chile. Si bien ambos son completamente diferentes, compartieron, dado el caso, una plataforma física común: el Desierto de Atacama.

En primer lugar, la "Historia del Salitre". Entre los años 1830 y 1940, situada en uno de los lugares más inhóspitos para la vida humana, logró su esplendor y auge a través de la explotación constante de los mineros del caliche. Hoy en día, si bien algunas oficinas se han transformado en importantes hitos turísticos, el porcentaje es mínimo. Las ruinas se han transformado a lo largo del desierto en fósiles de tiempos pasados esperando su desaparición entre los saqueos, la basura y la destrucción. Los cementerios, abandonados, algunos profanados y saqueados, conservan a aquellos anónimos que murieron en la inmensidad de la pampa desértica.

Y en segundo lugar, la "Historia de la Dictadura". Entre el período de 1973 a 1990, miles de chilenos sufrieron detenciones, torturas y muertes de familiares que hasta el día de hoy siguen desaparecidos. Si bien fue una realidad a nivel nacional, varios de ellos fueron muertos en el desierto y su paradero es 
1. Croquis.

2. Voladizo hacia el Desierto.
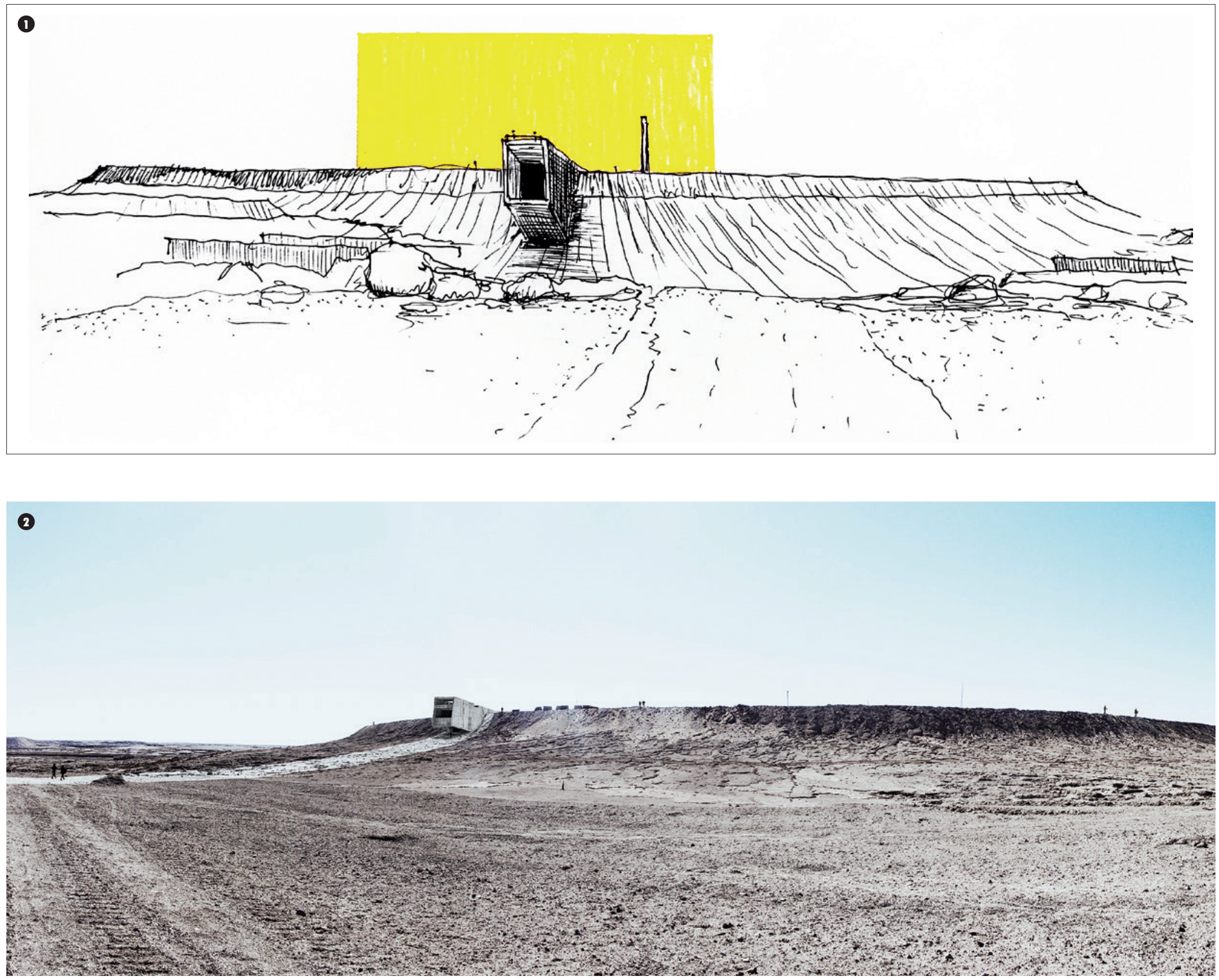

aún desconocido. Los constantes esfuerzos por parte de algunos por ocultar dichas violaciones a los derechos humanos, han provocado un olvido condicionado "como si nada hubiese sucedido", una realidad que sin duda debe ser transformada y puesta en valor socialmente para su comprensión.

\section{TEMA ARQUITECTÓNICO}

En base a lo anterior, el problema que busca abordar este proyecto se constituye principalmente por entender el "Olvido" como un fenómeno general, y dentro de la misma lógica evidenciar la deuda frente al cómo se ha hecho el proceso de materialización de la memoria.

Cabe mencionar que existe un amplio espectro, rico en expresiones, que busca trasladar las narrativas intangibles a operaciones materiales específicas. El problema se basa en que 
3. Mirador superior

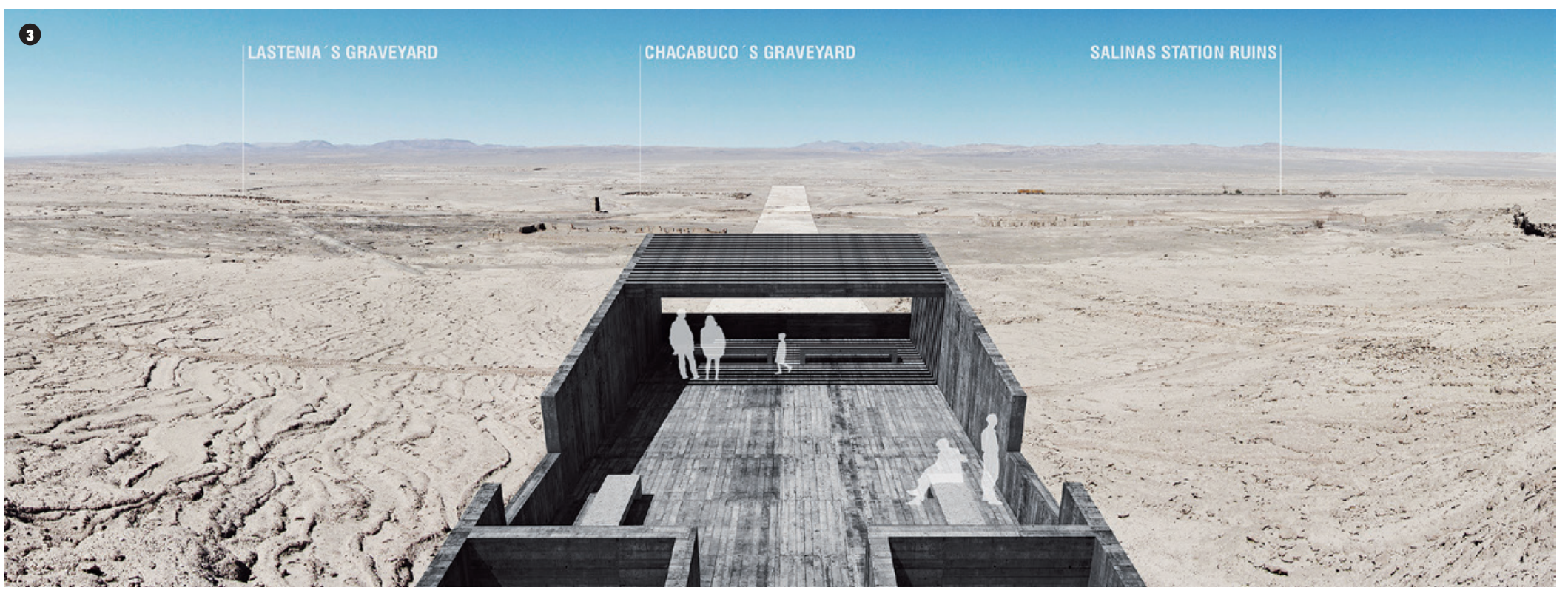

la mayoría de estos hitos conmemorativos responden a soluciones más bien estáticas, donde el vínculo con el evento se manifiesta a través de un objeto, pasando a ser un relación meramente visual más que experiencial. Robert Musil es claro al manifestar: "La cosa más sorprendente de los monumentos es que nunca los vemos. Nada en el mundo es tan invisible".

Bajo esta perspectiva el tema arquitectónico a trabajar se enmarca dentro de la siguiente pregunta: ¿Cómo materializar el olvido a través de la arquitectura para evocar la memoria?

\section{LUGAR}

La elección del lugar nace precisamente a partir de la ligazón con la premisa anterior. Trabajar en la Oficina Salitrera Chacabuco radica en que esta es testigo y testimonio tangible de ambas realidades.

Ubicada al costado de la Ruta 5, en el punto medio entre la carretera que une Antofagasta con Calama, la Oficina Salitrera Chacabuco (1924-1940) después denominada Campo de Prisioneros Chacabuco (1973-1975) es un ejemplo característico tanto del auge industrial salitrero como de la violación a los derechos humanos en el período de dictadura. Desde el punto de vista salitrero, Chacabuco se consolidó como el paradigma tecnológico de su época y fue considerada como modelo de configuración urbana con respecto al conjunto de oficinas de la región al planificar sin equívocos la organización programática del total. Por otro lado, durante la Dictadura, el Campo de Prisioneros fue uno de los centros de detención más grandes y aislados que hubo en el país, pasando por sus instalaciones más de 1.800 presos políticos.

Dadas estas características, junto con su condición de Monumento Histórico (paradójicamente decretado en 1971 por Salvador Allende), y su "buen" estado de conservación en comparación al conjunto de salitreras del Cantón Central -a pesar de los constantes saqueos-, la transforman en un lugar idóneo para intervenir y poner en valor.

\section{OBJETIVO/INTERVENCIÓN}

La respuesta o idea arquitectónica busca la creación de un proyecto que apele por sobre todas las cosas a la creación de un espacio de recordación, un "Espacio rememorativo" que juegue un rol activo dentro del proceso de construcción social de la memoria. Se busca poner en valor las historias ahí sucedidas y darles la relevancia que tuvieron para el país a través de una experiencia pregnante in situ. Cabe destacar que el objetivo no apunta a la realización de un museo como recopilador de archivos y documentos estáticos, sino más bien, narrar las historias desde el lugar mismo donde ocurrieron los hechos, creando un vínculo directo con la experiencia y el lugar.

Según la UNESCO, patrimonio se refiere a "la herencia cultural propia del pasado de una comunidad, con la que esta vive en la actualidad y que transmite a las generaciones presentes $y$ futuras" ${ }^{[1]}$. Desde esta perspectiva, el proyecto se desarrolla a partir del żcómo intervengo Chacabuco para lograr transmitir aquella herencia? En este sentido, entenderemos "INTERVENCIÓN" tal como lo definiría lgnasi de Solà-Morales:

[1] Extraído el jueves 08 de noviembre de 2012 de http://whc.unesco.org/en/about/ 
4. Huella intervención.

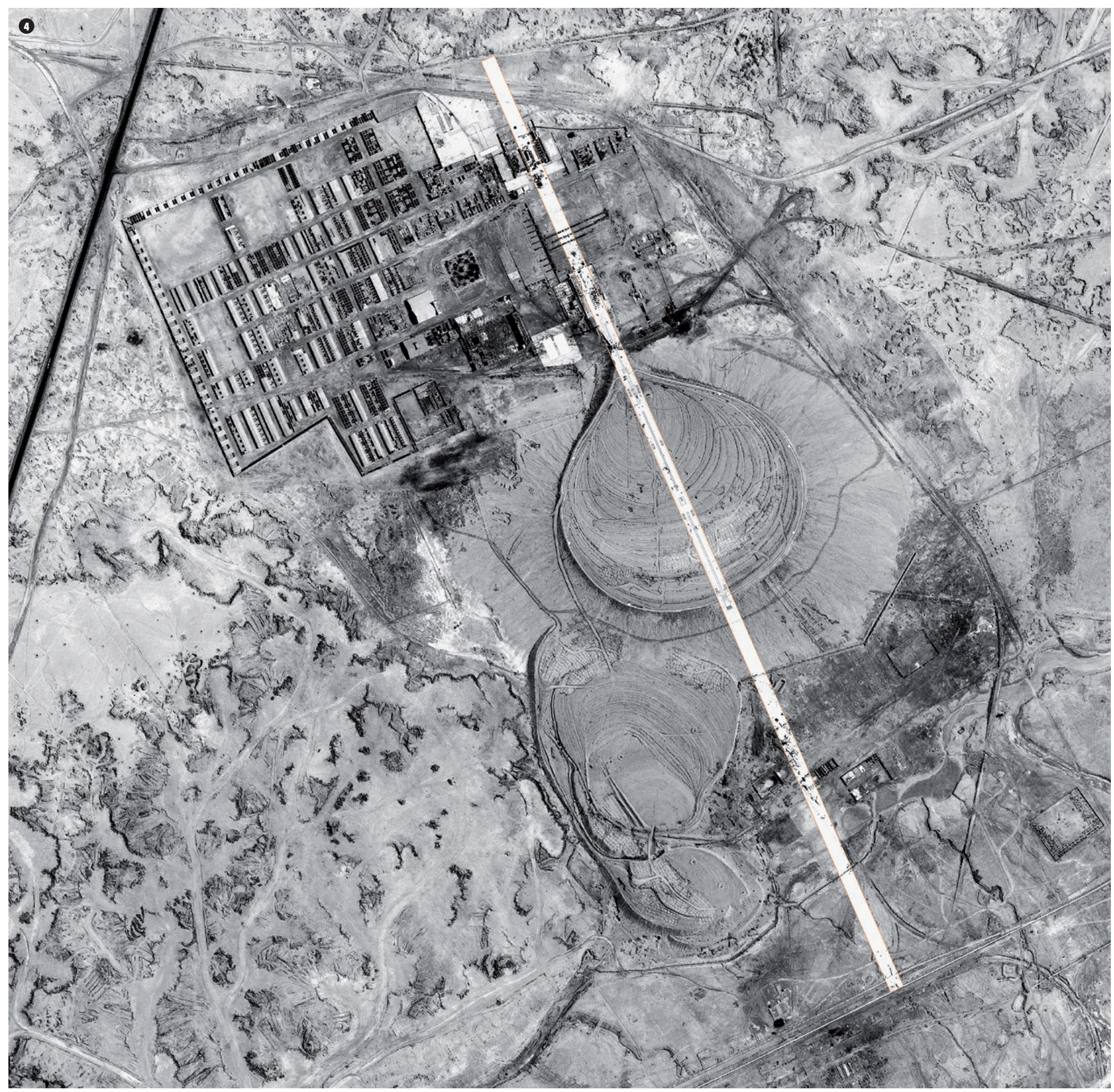


5. Plantas.

6. Plantas y corte.
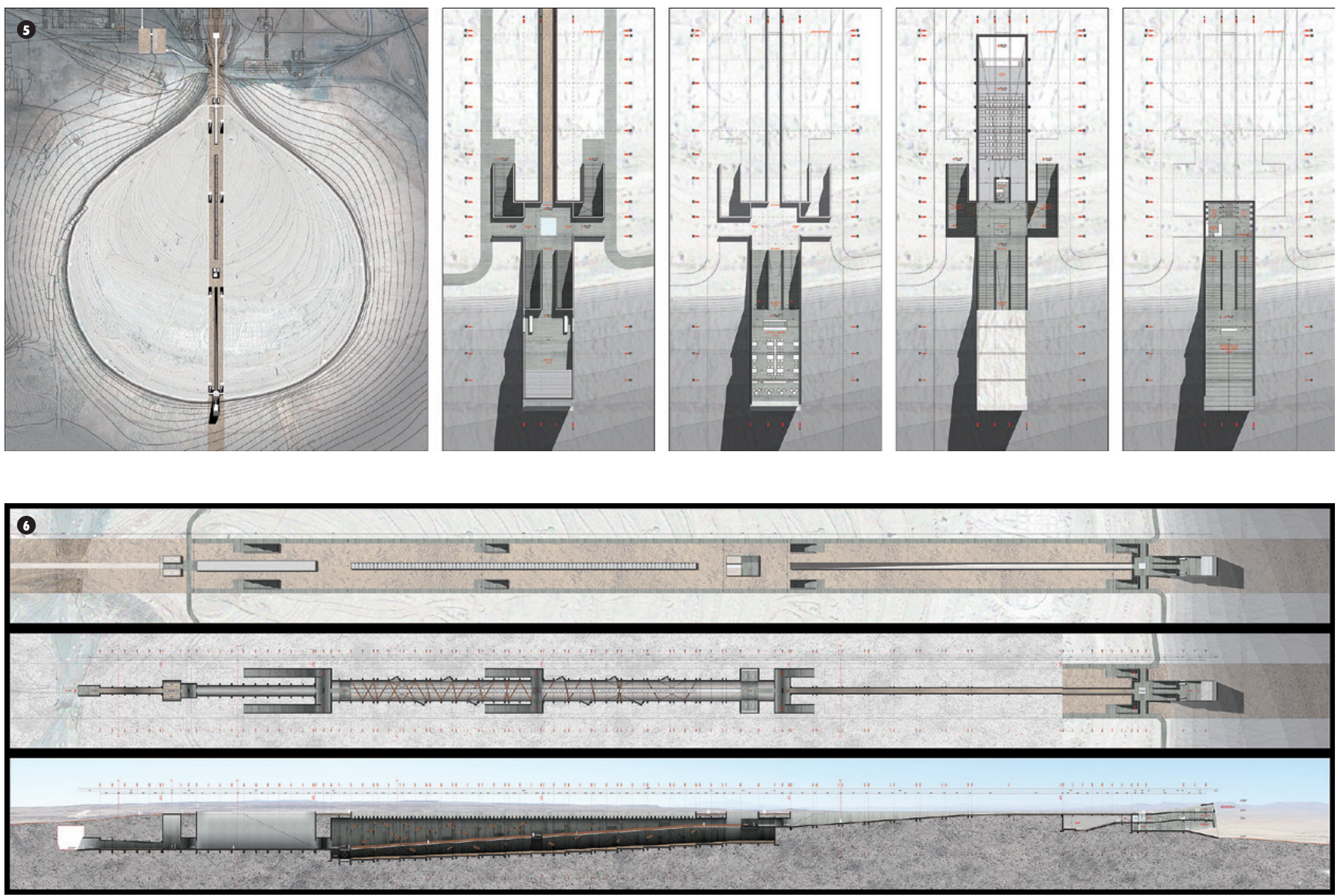

"la intervención es una operación estética, la propuesta imaginativa, arbitraria y libre por que se intenta no solo reconocer las estructuras del material histórico existente, sino también utilizarlas como una pauta analógica del nuevo artefacto edificado" (De Solà-Morales, 2006, p. 8).

$Y$ que se equipara al concepto de "INTERPRETACIÓN", entendiendo que la intervención en sí, es entendida como un "conflicto de interpretaciones".
Chacabuco es un "Lugar de Memoria", aquel espacio físico donde ocurrieron sucesos específicos y que la transforman en un "Museo de Sitio" por sí mismo. Las huellas presentes hasta el día de hoy se expresan por sí solas y dan a entender que más allá de intervenir considerablemente aquel patrimonio, se debe hacer lo contrario, son las mismas estructuras las que se manifiestan. Son protagonistas los elementos y artefactos que constituyen el conjunto histórico, en donde toda intervención debe apelar a la neutralidad, es aquella historia contenida la que debe hablar por sí misma y hacerse presente a través de su propia lógica. En este sentido, cuestionar la necesidad de museificar es esencial:

"La museificación produce la descontextualización de los objetos y los eventos. Al sacarlos de su contexto de uso, ya no es posible ninguna conexión emocional con la experiencia desde donde se extrajo, objetualiza el hecho, le extrae lo singular, lo distancia y congela" (SIIVA, M., ROJAS, F., 2010). 
7 y 8. Corte.

\section{PROYECTO}

La estrategia de proyecto se divide en tres grandes intervenciones: la primera "Intervención Rememorativa"; la segunda "Intervención Turística"; y la tercera "Intervención a Futuro". El presente texto se centrará en la más importante de las tres: ¿̇Cómo hacer de Chacabuco una Experiencia Rememorativa?

Para responder la pregunta anterior es necesaria la creación de una experiencia de recordación, lo cual se refiere principalmente a un recorrido por la salitrera definido en tres etapas. El recorrido se entenderá como un proceso cognitivo de aprendizaje, partiendo por el reconocimiento de una realidad, luego la interpretación de aquella y, finalmente, la síntesis y el entendimiento total de la misma:

\section{Reconocimiento - 2 Interpretación - 3 Síntesis}

Cada una de estas etapas está referida a un layer de memoria, las cuales se organizan desde el nivel más superficial al más profundo y se vinculan a un programa específico:

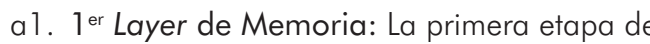
reconocimiento apela a la comprensión del PRESENTE, al reconocer la salitrera como tal. Que esta fue parte de una época y de una cultura, y que a su vez sirvió de soporte para otro tipo de funciones. Por lo tanto, es aquí donde es necesaria la definición de un recorrido por toda la salitrera y la demarcación de lo que fue el campo de prisioneros (hoy inexistente) que permita la comprensión total de la magnitud del conjunto.

a2. $2^{\text {do }}$ Layer de Memoria: La segunda etapa de interpretación apela a la comprensión del PASADO RECIENTE. En este sentido, entender la historia reciente de Chacabuco tanto en el período salitrero como en el período de campo de prisioneros. Poder ver las dinámicas del día a día en ambos momentos. Esto se traduce en la creación
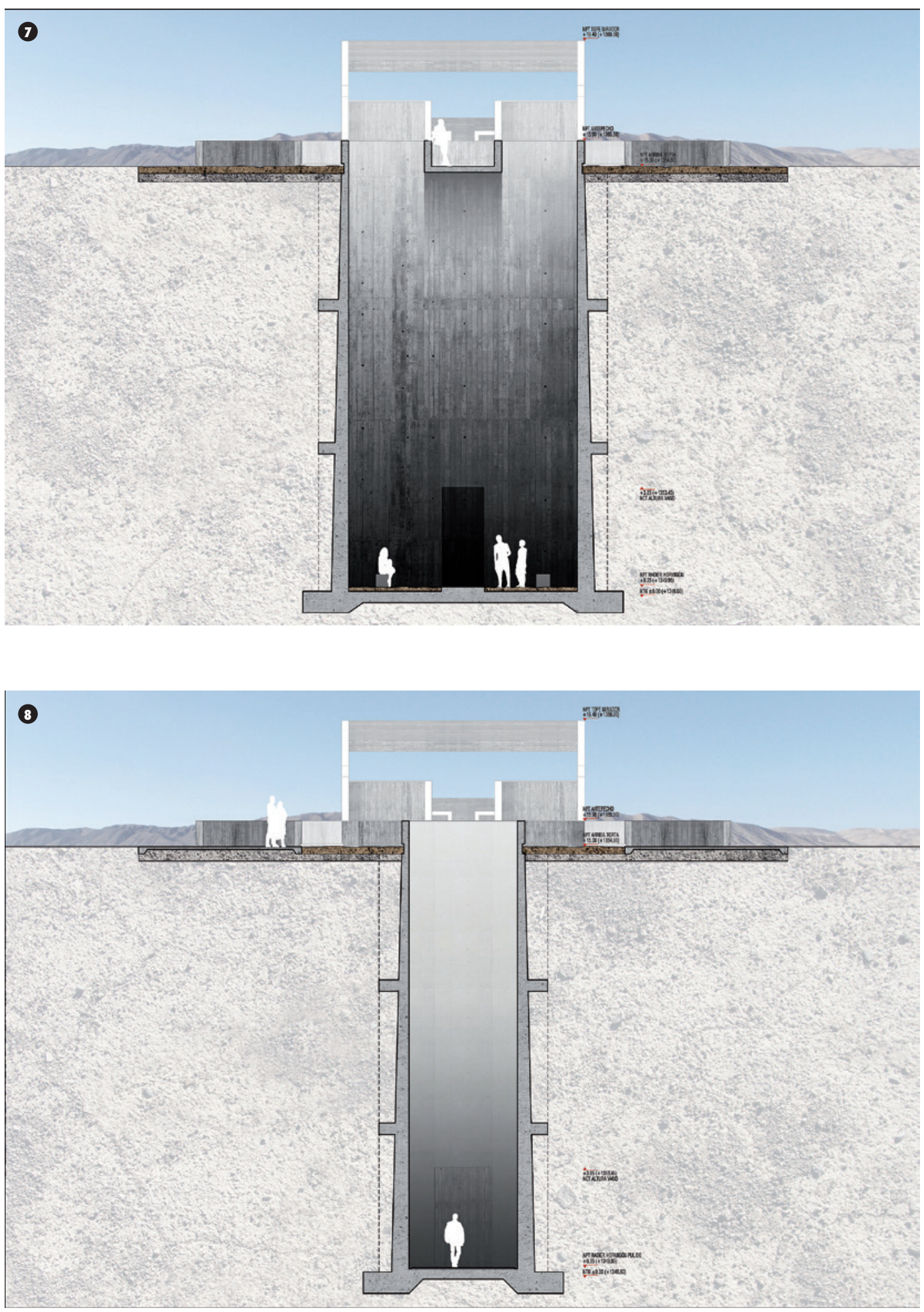
de un área de exposición que permita ver ambas realidades, a través de fotografías, cartografías, proyecciones y otros elementos, junto con evidenciar el estado actual con respecto al resto de las oficinas salitreras y campos de prisión y tortura.

a3. 3er Layer de Memoria: La tercera y última etapa de síntesis apela a la reflexión sobre el PASADO REMOTO. Esta etapa se entenderá como el remate o fin, donde luego de haber reconocido e interpretado la realidad de ambos períodos, y conocer cuál es su estado actual, poder a través de la creación de un espacio memorial -un memorial al olvido-, provocar una retrospección personal que vaya más allá de los dos hechos particulares (era del salitre y dictadura). Una retrospección que permita la reflexión al respecto del olvido y la historia a través de un espacio significante. Un espacio que retratará diversos ejemplos donde la historia es narrada por los vencedores y donde el hecho histórico busca ser eliminado.

"Tampoco los muertos -recuerda Benjaminestarán a salvo del enemigo cuando este venza. $Y$ este enemigo no ha cesado de vencer" (Collingwood-Selby, E., 2009, p. 22).

\section{MEMORIAL AL OLVIDO}

\section{Memorial Experiencial}

Situada en la etapa final -Síntesis- del recorrido por Chacabuco, la intervención es traducida como un "Espacio Memorial". Este es un memorial al olvido, la creación de un espacio significante que se transforme en la manifestación pura de su significado. El memorial busca evidenciar a través de una toma de decisiones específicas la condición de olvido y a través de dicha manifestación lograr "hacer visible lo invisible". Entendiendo que la Torta fue declarada Monumento Histórico el año 1989, la intervención en la superficie pretende ser mínima, apelando al desarrollo bajo tierra.
La primera estrategia para definir cómo desarrollar un memorial, pasa por entender cuáles han sido las formas en que estos se han materializado. Tal como se demostró al inicio, los memoriales han logrado un amplio espectro de expresiones que, en la mayoría de los casos, se traduce en una respuesta estática con un vínculo únicamente visual. A esto se suma, que dichas manifestaciones conmemorativas no se ubican en el lugar específico del hecho, sino más bien en un lugar aleatorio. En este sentido, la manera en que se ha traducido el lenguaje etéreo la memoria en una operación material (objetual-estática) y sin el vínculo con el lugar, ha provocado que la mayoría de dichas conmemoraciones se conviertan en elementos invisibles dentro de su contexto.

Ahora bien, existen ejemplos que han indagado en nuevas maneras de trabajar los memoriales generando un vínculo no a través de un objeto estático específico, sino más bien, con un lugar determinado. Estos, sin duda, logran crear un vínculo mayor con su contexto y permiten la consolidación de aquellos como "lugares culturales", tal como se plantean museos, centros culturales, parques u otros.

Por lo tanto, con dicha premisa, el memorial busca ir más allá de una respuesta estática, apelando a la creación de un "Memorial Experiencial" que permita ser una experiencia habitable, pregnante y significativa. De esta manera, se concibe como un elemento partícipe y activo dentro del recorrido total.

\section{Ubicación. ¿̇Por qué en la Torta de Ripios?}

Las Tortas de Ripio son los elementos más representativos que existen en la actualidad con respecto a las ruinas salitreras. Si bien las infraestructuras que conformaban a las oficinas han ido desapareciendo, las tortas son los elementos -que dada su magnitud-, se mantienen hasta el día de hoy. Estas son la acumulación de todos los restos del proceso salitrero. A medida que el proceso de lixivización extraía el nitrato de sodio contenido en los bloques de "caliche", los restos, eran transportados vía ferrocarril y depositados a diario en la zona específica donde se formaría, con el paso del tiempo, la torta final. Todos estos restos, que en definitiva eran simplemente "ripio", se transformaban en aquellas mecetas de enormes magnitudes (Torta de Chacabuco: $400 \times 400$ metros y una altura de 15 metros) que fueron definiendo un paisaje único y particular.

Ubicar el memorial en la torta de ripios responde a la "Metáfora" de entender el olvido como las sobras de la historia -de la memoria-, aquellos elementos que no merecen ser recordados y fueron desechados por algún motivo. En este sentido, las tortas de ripio, se comportan al igual que el olvido, son la escoria, los desechos y los restos de todo el proceso salitrero. De esta manera, se busca activar y poner en valor aquellos restos inutilizados, transformándolos en un contenedor activo de memoria. Simbólicamente esto permitirá ir en busca de la memoria en los restos mismos existentes, en este sentido, el olvido.

\section{Definiciones}

La definición de "memoria" la entenderemos a través de la lectura del libro La Memoria, la Historia, el Olvido, del filósofo francés Paul Ricoeur, a través de lo manifestado por Aristóteles. Se plantea que la memoria es del pasado, la presencia de lo ausente, de lo que fue, entendiendo la ausencia a partir de dos formas, la primera, como algo irreal perteneciente a la imaginación o imaginario, y la segunda, como algo real, algo que ha sido. Por lo tanto, la memoria en cuanto ausencia busca hacer presente "la ausencia que ha sido".

En este caso, entendiendo que la memoria es aquella ausencia que ha sido, el concepto de "Olvido", a grandes rasgos, será definido como "la ausencia de la ausencia", aquel vacío, aquella pérdida de continuidad en la memoria. 
9. Escantillón memorial.

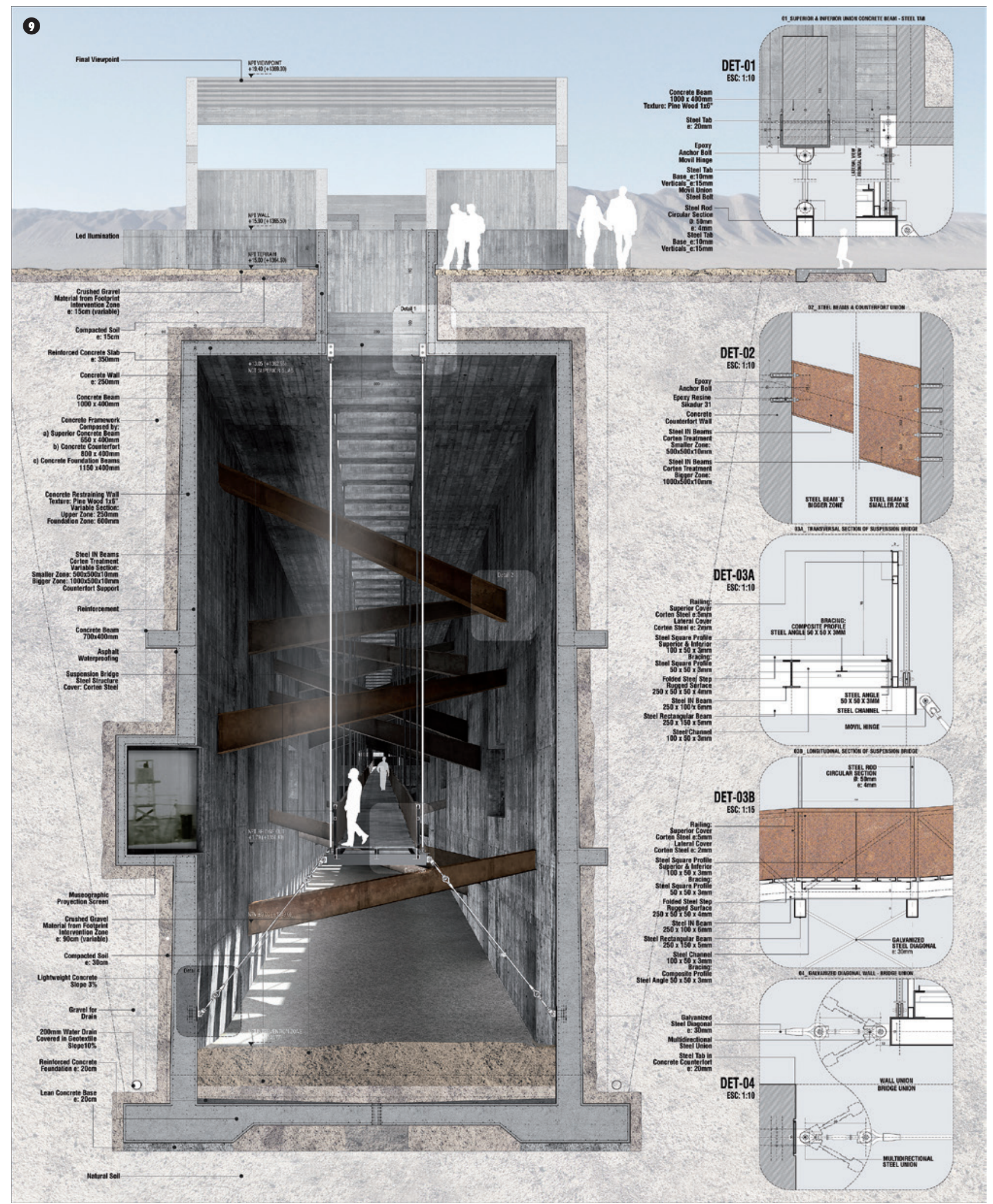


10 y 11. Maqueta.
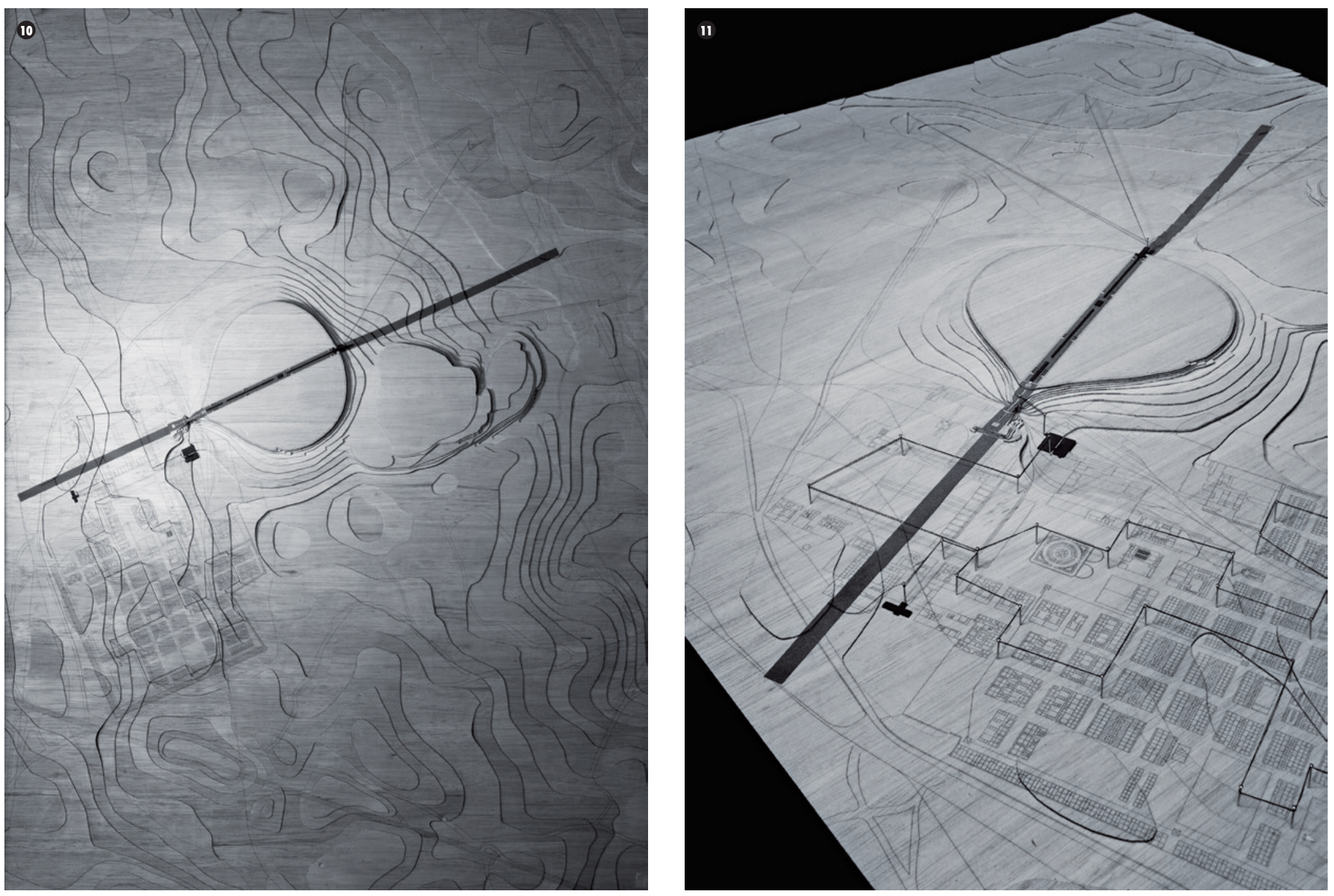

Aproximación Conceptual: ¿ Cómo entender el Olvido como concepto arquitecturizable?

Como se planteó anteriormente, el Olvido es aquel vacío, aquella pérdida de continuidad en la memoria. Dicha pérdida de continuidad, responde a tres conceptos claves:

a) Herida - b) Grieta - c) Fractura

a. Una herida es una lesión causada por un golpe, una caída, un corte, u otro tipo de accidente y que produce una discontinuidad de la anatomía normal. Es toda pérdida de continuidad secundaria a un traumatismo.

b. Una fractura es la separación bajo presión de dos o más piezas de un cuerpo sólido.

c. Una grieta es una abertura alargada, estrecha y no uniforme producto de la separación de dos materiales en una superficie o cualquier cuerpo sólido.

Considerando que los tres conceptos poseen en común la "pérdida de continuidad", entenderemos arquitectónicamente el concepto Olvido, como aquella discontinuidad, aque vacío en la materia que atravieza un cuerpo específico. Dicho cuerpo, en primera instancia será la Torta de Ripios.

Aproximación Formal: ¿̇Cómo me hago visible en el Desierto?

Es necesario entender que existen diversas formas de hacerse visible en el Desierto y que se manifiestan frecuentemente en el día a día de aquel territorio. Ahora bien, más allá de elegir una u otra forma particular, es necesario 
ir más allá de la comprensión literal de aquel lenguaje, y entender que la única condición que permite sobresalir como un elemento "ajeno" se fundamenta en entender la existencia de dos lenguajes, geometrías u órdenes absolutamente distintos. Existe el Orden Racional Humano, a través de una lógica particular, versus el Orden de la Naturaleza, a través del "caos", entendido como un orden distinto.

De esta manera, aquel elemento básico racional humano que permite la diferencia de ambos lenguajes es la "LÍNEA RECTA". Aquel elemento inexistente en el orden natural, organizado únicamente a través de elementos curvilíneos.

En este sentido, el memorial se expresará como una línea recta que difiera del orden natural del Desierto para manifestarse como aquella huella humana que busca manifestarse dentro de la vastedad. Las intervenciones de Richard Long (Land-Art) son claras al manifestar que la línea recta es el elemento geométrico distintivo de la creación racional humana.

¿Cómo Materializar el Olvido a través de la Arquitectura para Evocar la Memoria?

Surge una variable significativa frente a la reflexión de cómo abordar la extensión total de Chacabuco y no únicamente sus límites explícitos. En este sentido, un pequeño extracto del documental LA NOSTALGIA DE LA LUZ, es fundamental para comprender el porqué de la decisión tomada. El extracto, es una frase de Violeta Berríos, mujer de Calama que perdió a su familiares por la Dictadura y que se encuentran, hasta el día de hoy, desaparecidos en el Desierto: "Yo siempre he pensado, [...] que ojalá los telescopios no miraran solo al cielo, sino que pudieran traspasar la tierra para poderlos ubicar".

A través de un gesto únicamente simbólico y poético, el memorial busca ser un espacio reconocible y visible al dar vuelta los telescopios. Si bien en primera instancia se manifestó que el memorial -línea recta- abarcaría únicamente la torta de ripios, este se conserva pero se expande a través de una huella que se comporta como una cicatriz -vacío =olvido - en la memoria (extensión del área de Chacabuco). Una grieta-herida-fractura que se demarca en el terreno con una extensión de 1,6km de largo, definida por los límites virtuales del área entre el campo minado y la línea del ferrocarril principal Antofagasta-Oruro, entendiendo la historia de Chacabuco como la transformación de Oficina Salitrera a Campo de Prisioneros. Finalmente, el Olvido se materializa a través de una línea recta que genera un vacío en Chacabuco manifestando en sí mismo la existencia de aquella memoria. El vacío es aquella cicatriz que evidencia la existencia de aquel espacio y lo demarca a través del lenguaje racional humano distinto al orden natural.

"Invertir los telescopios", significa hacer de Chacabuco una pausa, un lugar para observarnos, para entender el frenesí de la sociedad contemporánea y reflexionar frente al fenómeno del olvido como evidencia de aquella realidad.

\section{BIBLIOGRAFÍA}

Collingwood-Selby, E. (2009). El Filo Fotográfico de la Historia. Walter Benjamin y el Olvido de lo Inolvidable. Santiago: Editorial Metales Pesados.

De Solà-Morales, I. (2006). Intervenciones. Barcelona: Editorial Gustavo Gili.

Gúzman, P. (Director). (2010). Nostalgia de la luz. Chile: Francia: Atacama Productions (Renate Sachse).

Ricoeur, P. (2008). La Memoria, la Historia, el Olvido. Buenos Aires: Fondo de Cultura Económica.

Silva, M., Rojas, F. (2010). Ponencia "El manejo urbano-arquitectónico de la memoria urbana traumatizada". Seminario Internacional Ciudad y Memorias. Santiago: Corporación Parque por la Paz Villa Grimaldi. 